\title{
LED Lightbulbs as a Source of Electricity Saving in Buildings
}

\author{
Akhtar Zeb ${ }^{1}$, Marcelo de Andrade Romero², Dinar Baiguskarov, ${ }^{3, *}$ Sanzhar Aitbayev ${ }^{3}$, \\ Ksenia Strelets $^{3}$ \\ ${ }^{1}$ University of Engineering \& Technology Peshawar, Khyber Pakhtunkhwa, Pakistan. \\ ${ }^{2}$ University University of Sao Paulo, Rua da Reitoria, 109 - Butanta, Brazil \\ ${ }^{3}$ Peter the Great St. Petersburg Polytechnic University, Politechnicheskaya, 29, St. Petersburg, \\ 195251, Russia
}

\begin{abstract}
Today a number of renewable energy technologies are available for power generation, but fossil fuels are still providing a dominant share nevertheless. In order to decrease the electric bill and save our environment, energy conservation is always crucial. In this paper a very interesting idea is presented which is economically viable to reduce electricity usage in our buildings. An effort has been made to estimate the amount of energy that could be saved in the dormitory section of the IMOP building in Russia. Although there are many ways to reduce the consumption of electricity in this building but here the emphasis is on changing light bulbs inside the rooms, kitchen, toilet and bathroom of each apartment. The scope of the study is to figure out monthly electricity saving by replacing traditional light bulbs by LED light bulbs in the building under consideration. The total investment required and the payback period is also presented.
\end{abstract}

\section{Introduction}

Lighting represents almost $20 \%$ of global electricity consumption. This consumption is similar to the amount of electricity generated by nuclear power. The latest IEA estimates show the total savings potential in residential and services lighting at more than $2.4 \mathrm{EJ}$ per year by 2030 [1]. The energy savings potential in the buildings sector is massive. Globally, the wide deployment of best available technologies and efficiency policies could yield annual savings in building final energy use in the range of $53 \mathrm{EJ}$ by 2050 (a 29\% reduction in projected building energy consumption relative to a business-as-usual scenario in 2050) - equivalent to the combined energy use of buildings in China, France, Germany, Russia, the United Kingdom, and the United States in 2012 (IEA, 2015a). Capturing this energy savings potential would deliver a range of benefits: lower electricity and fuel costs for businesses and households; greater reliability in meeting energy demand without costly infrastructure and disruptions; and reductions in emissions of heat-trapping GHGs and other pollutants that pose a threat to human health [2].

\footnotetext{
* Corresponding author: dinarbay@gmail.com
} 
With the emerging concept of retrofitting, it is desirable to spare as many kilowatts of power as possible. This not only results in better utilization of energy inside buildings but also helps us to cut our electricity bill. It is quite feasible and economically viable by just making few changes inside our buildings or homes, for instance, changing paint color of the walls, choosing windows that prevent unnecessary heat transfer and even the simplest trick is to use LED light bulbs of suitable illuminance and wattage instead of traditional light bulbs.

In almost every working area appropriate lighting is the key to higher efficiency. It is also associated with educational field especially the student's dorms. The student's dormitory is an important part of the education area and should be provided with suitable lighting conditions. It should be equipped according to the students visual comfort, however, should be made available in a way to reduce the energy consumption that would result in lower rent charges. In order to achieve this goal it is recommended to replace the traditional light bulbs by LEDs.

In this report a case study is made to represent the importance of changing LED lamps in the dormitory of international students known as IMOP located in Saint Petersburg, Russia.

The aim of this paper is to present:

- The current electricity consumption;

- Total investment required for changing LED light bulbs in all apartments;

- The payback period;

- The amount of electricity saving on monthly basis.

The current scenario of the building focusing on the calculations of daily electricity utilization and monthly electricity bill, which served as the basis for annual projections. The total investment required for LEDs light bulbs is estimated, the payback period is calculated and the amount of electricity that could be saved is also reported.

\section{Light Emitting Diodes (LEDs) light bulbs}

Traditional incandescent bulbs use a lot of energy to produce light and are no longer manufactured. $90 \%$ of the energy is given off as heat. That lost energy is money we are throwing away. Three of the most common energy-efficient lighting types include halogen incandescents, CFLs, and LEDs. LEDs use only $20 \%-25 \%$ of the energy and last up to 25 times longer than the traditional incandescent bulbs they replace. LEDs use $25 \%-30 \%$ of the energy and last 8 to 25 times longer than halogen incandescent [3]. LED bulbs are currently available in many products such as replacements for $3 \mathrm{~W}, 4 \mathrm{~W}, 5 \mathrm{~W}, 6 \mathrm{~W}, 10 \mathrm{~W}$, $12 \mathrm{~W}, 40 \mathrm{~W}, 60 \mathrm{~W}$, and $75 \mathrm{~W}$ traditional incandescents, reflector bulbs often used in recessed fixtures, and small track lights [4]. The LED lamps have very high efficiency and can be used easily in place of traditional light source [5]. Also, it acts as an environmental light source from manufacturing to disposal [6]. There are many different applications, for instance; modern household equipment [6], head light and brake lights in automobiles [8], street lights [9], interior household illumination [10], hospital diagnostic and treatment room [11]. LED lighting is very different from other lighting sources such as incandescent bulbs and CFLs.

Key differences include the following [12]:

- Light Source: LEDs are the size of a fleck of pepper, and a mix of red, green, and blue LEDs is typically used to make white light.

- Direction: LEDs emit light in a specific direction, reducing the need for reflectors and diffusers that can trap light. This feature makes LEDs more efficient for many uses such as recessed downlights and task lighting. With other types of lighting, the 
light must be reflected to the desired direction and more than half of the light may never leave the fixture.

- Heat: LEDs emit very little heat. In comparison, incandescent bulbs release $90 \%$ of their energy as heat and CFLs release about $80 \%$ of their energy as heat.

Some of the distinctive features of LEDs are [13]:

1. A light-emitting diode, or LED, is a type of solid-state lighting that uses a semiconductor to convert electricity into light. Today's LED bulbs can be six-seven times more energy efficient than conventional incandescent lights and cut energy use by more than 80 percent.

2. Good-quality LED bulbs can have a useful life of 25,000 hours or more -- meaning they can last more than 25 times longer than traditional light bulbs. That is a life of more than three years if run 24 hours a day, seven days a week.

3. Unlike incandescent bulbs - which release 90 percent of their energy as heat -- LEDs use energy far more efficiently with little wasted heat.

4. From traffic lights and vehicle brake lights to TVs and display cases, LEDs are used in a wide range of applications because of their unique characteristics, which include compact size, ease of maintenance, resistance to breakage, and the ability to focus the light in a single direction instead of having it go every which way.

5. LEDs contain no mercury, and a recent Energy Department study determined that LEDs have a much smaller environmental impact than incandescent bulbs. They also have an edge over compact fluorescent lights (CFLs) that expected to grow over the next few years as LED technology continues its steady improvement.

6. Since the Energy Department started funding solid-state lighting R\&D in 2000, these projects have received 58 patents. Some of the most successful projects include developing new ways to use materials, extract more light, and solve the underlying technical challenges. Most recently, the Energy Department announced five new projects that will focus on cutting costs by improving manufacturing equipment and processes.

7. The first visible-spectrum LED was invented by Nick Holonyak, Jr., while working for GE in 1962. Since then, the technology has rapidly advanced and costs have dropped tremendously, making LEDs a viable lighting solution. Between 2011 and 2012, global sales of LED replacement bulbs increased by 22 percent while the cost of a 60 -watt equivalent LED bulb fell by nearly 40 percent. By 2030, it's estimated that LEDs will account for 75 percent of all lighting sales.

8. In 2012, about 49 million LEDs were installed in the U.S. - saving about $\$ 675$ million in annual energy costs. Switching entirely to LED lights over the next two decades could save the U.S. $\$ 250$ billion in energy costs, reduce electricity consumption for lighting by nearly 50 percent and avoid 1,800 million metric tons of carbon emissions.

\section{What's a lumen?}

Lumens measure how much light you are getting from a bulb. More lumens means it's a brighter light; fewer lumens means it's a dimmer light.

Lumens are to light what:

- Pounds are to bananas;

- Gallons are to milk.

Lumens let you buy the amount of light you want. So, when buying your new bulbs, think lumens not watts.

We typically buy things based on how much of it we get, right? When buying milk, we buy it by volume (gallons). So, why should light be any different? For decades, we have been buying light bulbs based on how much energy they consume (watts) - no matter how much 
light they give us (lumens). When you're shopping for light bulbs, compare lumens to be sure you're getting the amount of light, or level of brightness, you want.

\section{Current scenario}

In this work the dormitory portion of the building is considered. There are total nine floors. The first floor consists of many different offices and other facilities for the students like medicine room, laundry, etc. Therefore, only 8 floors are examined in this study. There are total of 15 apartments on a floor. Each apartment consists of two bedrooms, kitchen, toilet and a bathroom. Figure 1 depicts the number of lamps inside an apartment.

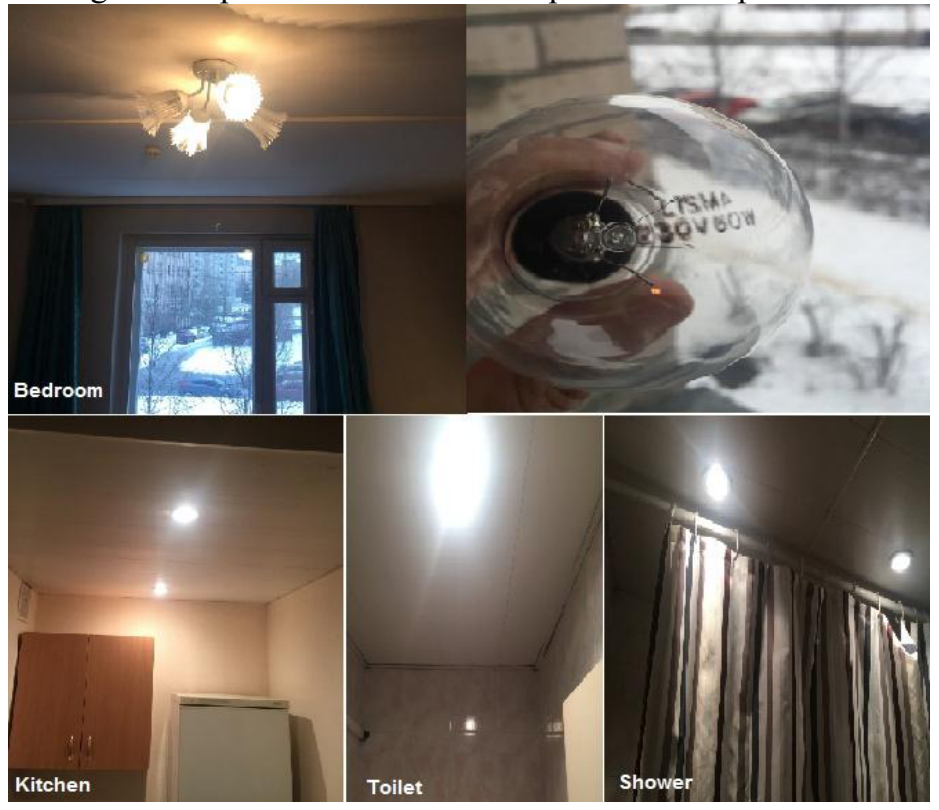

Fig. 1. Lamps in apartment.

The current total power requirement of an apartment is presented in Table 1 (the study lamps are excluded).

Table 1. Current consumption of an apartment.

\begin{tabular}{|l|c|c|c|}
\hline \multicolumn{1}{|c|}{ Apartment } & Number of lamps & Watt & Total Wattage \\
\hline Bedroom 1 & 4 & 60 & 240 \\
\hline Bedroom 2 & 4 & 60 & 240 \\
\hline Kitchen & 2 & 50 & 100 \\
\hline Toilet & 1 & 50 & 50 \\
\hline Shower & 2 & 50 & 100 \\
\hline \multicolumn{2}{|c|}{ Total current power requirement of an apartment } & $730 \mathrm{~W}$ \\
\hline
\end{tabular}

The daily electricity usage and monthly bill of an apartment is calculated with the assumptions that the light bulbs are turn on for the following periods of time: 
Bedrooms: $8 \mathrm{~h} /$ day;

Kitchen: 16h/day;

Toilet \& bathroom: $4 \mathrm{~h} /$ day.

Current electricity consumption and monthly \& annual bill of an apartment:

Electricity consumption per day: $6.04 \mathrm{KWh}$;

Total consumption per month: $181.2 \mathrm{KWh}$;

Monthly electricity bill: 543.6 rubs $(1 \mathrm{KWh}=3 \mathrm{rub})$;

Annual electricity bill: 6523.2 rub.

\section{After retrofitting}

In order to reduce the electricity consumption, appropriate LED light bulbs were chosen having the same amount of lumens but low wattage. In our case the LED light bulbs of 6 and $10 \mathrm{~W}$ are the suitable ones. With the usage of these lamps, the total power requirement of an apartment would be as under as shown in Table 2.

Table 2. Total power requirement of an apartment after retrofitting.

\begin{tabular}{|l|c|c|c|}
\hline \multicolumn{1}{|c|}{ Apartment } & Number of lamps & Watt & Total Wattage \\
\hline Bedroom 1 & 4 & 10 & 40 \\
\hline Bedroom 2 & 4 & 10 & 40 \\
\hline Kitchen & 2 & 6 & 12 \\
\hline Toilet & 1 & 6 & 6 \\
\hline Shower & 2 & 6 & 12 \\
\hline \multicolumn{2}{|c|}{ After Retrofitting the total power requirement of an apartment } & $110 \mathrm{~W}$ \\
\hline
\end{tabular}

After retrofitting, electricity consumption and monthly bill of an apartment:

Electricity consumption per day: $0.904 \mathrm{KWh}$;

Total consumption per month: $27.12 \mathrm{KWh}$;

Monthly electricity bill: $81.36 \mathrm{rub}(1 \mathrm{KWh}=3 \mathrm{rub})$;

Annual electricity bill: 976.32 rub.

\section{Results}

With a vacancy rate of $25 \%$, there are 100 occupied and 30 vacant flats in the building (the vacancy rate may change). Therefore, for the 100 occupied flats the total investment required for changing lamps, the electricity saving and payback period would be as under:

Total investment for changing lamps: $273.000 \mathrm{rub}$;

Amount of electricity saving per month: $15.408 \mathrm{KWh}$.

Annual Economy by reducing electricity bill: 554.688 rub. Payback period: 6 months.

\section{Conclusion}

In this study an idea of electricity saving inside buildings has been presented. The current electricity consumption with traditional lights is calculated. The LED lights are used replacing the traditional lights and the electric consumption is recalculated. The amount of electricity saving is figure out. The total investment required is estimated and thus the payback period is presented. It is concluded that replacing the present traditional lights by 
LED lights in our buildings would not only result in low electric bills but also in energy conservation. Furthermore, the process is quite feasible and economically viable.

\section{References}

1. International Energy Agency

2. Information on http://iea.org/topics/energyefficiency/subtopics/lighting

3. International Partnership for Energy Efficiency Cooperation (IPEEC) \& International Energy Agency (IEA), 'Building Energy Performance Metrics', Supporting Energy Efficiency Progress in Major Economies

4. Information on www.mrs.680org/bulletin

5. Information on http://energy.gov/energysaver/choices-save-you-money

6. Safaa Alzubaidi and Prashant kumar Soori, J.Light \& Vis. Env.,36(1), 23-31 (2012)

7. R. Devonshire, J. Light \& VisEnv., 32, 275-287 (2008)

8. N. Zheludev, Nature Photonics, 1, 189-192 (2007)

9. S. Liu, A. Minato, S. Ozawa and M. Nakagawa, J. Light \& Vis.Env, 31, 65-69 (2007)

10. M.A.Dalla Costa, L.Schuch, L.Michels, C.Rech, J.R. Pinheiro and G.H.Costa, "Autonomous Street Lighting System based on Solar Energy and LEDs", 1143-1148 IEEE, (2010)

11. Wen-Shing sun, Chih-Hsuan Tsuei, and Yi Han huang, "Simulating the Illuminance and Efficiency of the LEDs used in General Household Lighting", Science Direct, Physics Procedia, 19, 244-248 (2011)

12. P. Sathya \& Dr. R. Natarajan, "Design of Energy Efficient lighting system for Educational Laboratory".

13. L. Svatovskaya, A. Sychova, M. Sychov, V. Okrepilov, MATEC Web of Conferences, 53, Article Number 01023 (2016)

14. Information on http://energy.gov/articles/top-8-things-you-didn-t-know-about-leds

15. Information on http://energy.gov/energysaver/lumens-and-lighting-facts-label 